\title{
Genişleyebilir Killerin Baskın Olduğu Kurak Alanlarda Buğdayda Farklı Üst Gübre Kullanımlarının Araştırılması
}

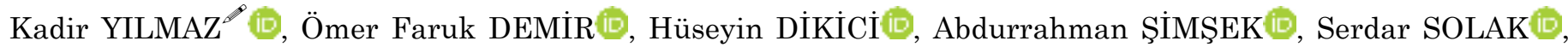 \\ Yaşam KENGER (D), Zehra AĞAOĞLU (D) \\ Kahramanmaraş Sütçü İmam Üniv., Ziraat Fakültesi, Toprak Bilimi ve Bitki Besleme Bölümü, Kahramanmaras \\ ${ }^{1}$ https://orcid.org/0000-0002-0539-4534, ${ }^{2}$ https://orcid.org/0000-0002-0636-5225, ${ }^{3}$ https://orcid.org/0000-0002-1335-4380 \\ ${ }^{4} \mathrm{https}: / /$ orcid.org/0000-0001-5844-8471, ${ }^{5} \mathrm{https} / / /$ orcid.org/0000-0003-0338-2190, ${ }^{6} \mathrm{https}: / /$ orcid.org/0000-0002-5202-3269 \\ ${ }^{7}$ https://orcid.org/0000-0001-8107-8720 \\ $\bowtie$ : kyilmaz@ksu.edu.tr
}

\section{ÖZET}

$\mathrm{Bu}$ çalışmada, kurak koşullarda yetiştirilen buğdayda geç evrede verilen ikinci üst gübre azotunun, bitkiye erken evrede amonyum ve üre formunda verilerek, azotun 2:1 tipi kil mineralleri tarafından fiksasyonu ile kurak dönemde bitkinin azot ihtiyacının toprakta fikse edilen amonyum formundaki azotun serbestlenmesi ile karşılanması amaçlanmıştır. Araştırma sonucunda, üre ve amonyum formunda tek sefer azot uygulamasındaki tane veriminin, iki evrede verilen amonyum nitrat uygulamasından daha yüksek olduğu, bin dane ağırlığının amonyum sülfat uygulamasında en yüksek, amonyum nitrat uygulamassında en düşük olduğu bulunmuştur. Sonuç olarak, azotlu gübrelerin kurak alanlarda smektit ve vermikülitce baskın topraklarda, erken dönemde tek seferde üre veya amonyum formunda toprağa verilmesinin, iki defada amonyum nitrat azotu formunda verilmesinden daha etkili olduğu görülmüştür.

\section{Araştırma Makalesi}

\author{
Makale Tarihçesi \\ Geliş Tarihi : 24.10 .2018 \\ Kabul Tarihi : : 15.01.2019
}

\section{Anahtar Kelimeler}

Buğday

Amonyum Fiksasyonu

Smektit

Vermikülit

\section{Effect of Different Nitrogen Top Dressing Strategies on Rain-fed Wheat Yields Grown in a Soil Dominant with Expanding Clay Minerals}

\begin{abstract}
In this study, it was proposed that nitrogen demands of rainfed wheat plants may be met by the release of ammonium fixed in $2: 1$ clay minerals. In order to do that single top dressing of nitrogen given in the forms of urea or ammonium in the early stage of plant growth and two split applications of $\mathrm{N}$ as ammonium-nitrate were compared in rain-fed wheat plants. As a result of the study, grain yields obtained from single applications of urea and ammonium were found to be higher than two split applications of ammonium nitrate. Thousandgrain weight was found to be the highest with the ammonium sulfate application and the lowest with the ammonium nitrate application. It was seen that applying nitrogen fertilizers to the soil which is dominant with expanding smectite and vermiculate clay minerals in the forms of urea and ammonium at once in the early stage is more effective than two split applications as ammonium nitrate.
\end{abstract}

\section{Research Article}

$\begin{array}{ll}\text { Article History } & \\ \text { Received } & : 24.10 .2018 \\ \text { Accepted } & : 15.01 .2019\end{array}$

\section{Keywords}

Wheat

Ammonium Fixation

Smectite

Vermiculite

To Cite : Yılmaz K, Demir ÖF, Dikici H, Şimşek A, Solak S, Kenger Y, Ağaoğlu Z 2019. Genişleyebilir Killerin Baskın Olduğu Kurak Alanlarda Hububatta Farklı Üst Gübre Kullanımlarının Araştırılması. KSÜ Tarım ve Doğa Derg 22(2): 306314. DOI: 10.18016/ksutarimdoga.vi.474168.

\section{GİİŞ}

Kil mineralleri, bitki için gerekli olan elementlerin belirli bir kısmı için element değişiminin bir aracıdır. Değişim zonunun yüzey katmanındaki değişebilir elementler bitkilerin alımı için uygun durumdadır. Kalsiyum ve magnezyum gibi görece olarak fazla miktarda olan elementler, değişebilir katyonlar olarak killerin yüzeyine bağlanmaktadır. Bununla birlikte, bazı elementler ise killerin tabakaları arasındaki alanlarda oldukça sıkı bir şekilde tutulmaktadır. Bunlar içerisinde en önde gelenler amonyum ve potasyum iyonlarıdır. Amonyum iyonu, $\mathrm{NH}_{4}$, bitki kök sisteminde kolayca absorbe edilmekte ve bitkiler için önemli bir azot kaynağı olmaktadır. Amonyum iyonu, 
yaklaşık olarak bir potasyum iyonunun çapındadır ve çoğunlukla killerin içinde ve yüzeyinde potasyuma benzer şekilde bulunmaktadır. Amonyumun, 2:1 tipi kil minerallerinin tabakaları arasında bir çeşit amonyum mika üreterek form aldığ bilinmektedir (Sucha ve ark., 1998). Smektitler de amonyumu tabakalar arasında değişebilir iyon olarak tutmaktadır (Sucha ve Sirahova, 1991).

\section{Amonyum Fiksasyon Mekanizması}

Page ve Baver (1939)'in ileri sürdüğü ve üzerinde fikir birliği bulunan kafes-boşluk (lattice-hole) teorisine göre, genişleme özelliğine sahip 2:1 tipi kil minerallerinin tabakaları arasındaki yüzeyler, altıgen olarak dizilmiş bir oksijen tabakası ihtiva etmektedir ve boşluğun çapı $2.8 \mathrm{~A}^{0}$ dur. Killer suyunu kaybettiği zaman tabakalar daralmakta ve iyonlar etraflarındaki su moleküllerini kaybederek susuz iyonik çaplara erişmektedir. Çapları kristal kafesler içerisindeki boşluklara uyan katyonlar ise sıkı bir şekilde tutunmaktadırlar.

Amonyum fiksasyonu "amonyum iyonlarını topraklardaki mineral ve organik fraksiyonlar tarafından katyon değişiminin genel metodları ile görece değişemez bir biçimde adsorbsiyonu ve absorbsiyonu" olarak tanımlanabilmektedir (Osborne, 1976; SSJA, 1984). Toprağın güçlü asitlerle yakılması ile kil minerallerinden ortaya çıkarılan organik veya amonyumfosfatlar şeklinde toprağa bağlanmış (Frye ve Hutcheson, 1981) $\mathrm{NH}_{4}$ ' u ayırmak için Osborne (1976) "ilave $\mathrm{NH}_{4}$ " ve Mengel ve Scherer (1981) ise "değişemez $\mathrm{NH}_{4}$ " terimlerini önermişlerdir. Eski araştırmalarda fikse amonyumun sadece çok az bir kısmının bitki ve mikroorganizmalara yararlı olduğu sonucuna varılmışsa da (Allison ve ark., 1951,1953; Axley ve Legg, 1960; Lutz, 1966 ), son otuz ylldaki çalışmalarda fikse amonyumun serbestlenebileceği ve bitkiler tarafından kullanılabileceği varsayılmaktadır (Kudeyarov, 1981; Nommik, 1981; Mengel ve Scherer, 1981, 1986; Nommik ve Vahtras, 1982; Preston, 1982; Scherer, 1984, 1987, 1993; Lu ve ark., 2010).

Hem illit de hem de vermikülitte gerçekleşen, $\mathrm{H}^{+}$ile $\mathrm{NH}_{4}{ }^{+1}$ un yer değişimi, mevcut minerale bağlı olduğu kadar bitki çeşidi ile de ilişkilidir. Bu nedenle kil yüzeylerinde ve içinde gerçekleşen potasyum ve amonyum fiksasyonlarmm kondisyon ve mekanizmaları, besin elementlerini ekstrakte eden mevcut bitkilerin taleplerine uygun olarak bir kaç değişkene bağlıdır. Bitkiler için potasyum ve amonyum iyonları hayati önem taşıdığından, bitkilerin ihtiyaçlarını sürdürülebilmesi için bazı mekanizmalar mevcut olmak zorundadır.

\section{Fiksasyon Kapasiteleri}

Kil minerallerinin amonyum fikse etme özellikleri iki farklı kategoride değerlendirilmelidir. Bunlardan ilki önceden fikse edilmiş olan $\mathrm{NH}_{4}{ }^{+}$, diğeri ise amonyum fikse etme kapasiteleridir. Önceden fikse edilmiş olan amonyum yönünden incelendiğinde; illit en fazla, vermikülit orta derecede ve montmorillonit ise en az fikse edilen amonyuma sahiptir. Toprağa uygulanan amonyum fiksasyon kapasiteleri yönünden ele alındığında ise en yüksek fiksasyon kapasitesi vermikülite aittir. İkinci olarak illit ve en az montmorillonit amonyum fikse etmektedir. 1:1 tipi kaolinitin ise çok az ya da hiç $\mathrm{NH}_{4}{ }^{+}$fikse etmediği kabul edilmektedir (Sağlam, 1974).

Amonyum fiksasyonu illit, vermikülit ve montmorillonit gibi 2:1 tipi kil minerallerinde oldukça fazladır. Kil mineralleri $\mathrm{NH}_{4}{ }^{+}$ve $\mathrm{K}^{+}$tarafından dengelenmiş negatif yüklere sahiptir. $\mathrm{NH}_{4}$ 'un fiziksel yapısı K'a yakından benzemektedir çünkü her iki iyon da benzer iyonik çapa ve düşük hidrasyon enerjisine sahiptir (Nieder ve ark., 2011). $\mathrm{NH}_{4}{ }^{+}$ve $\mathrm{K}^{+}$ fiksasyonlarından her ikisi için de aynı mekanizma sorumludur ve her ikisi de 2:1 kil mineralleri içerisindeki bazal oksijen düzlemindeki ditrigonal yuvalara tam olarak uyum göstermektedir. Her iki katyonun da kil mineralleri tabakaları arasına girmesi kil tabakalarının $1 \mathrm{~nm}$ 'ye daralmasına ve $\mathrm{NH}_{4}{ }^{+}$ve $\mathrm{K}^{+}$ iyonlarının silikat tabakaları arasında kıstırılmasına ve değişebilir reaksiyonlarla büyük oranda içine kapanmasına neden olmaktadır (Nommik, 1965). Bu nedenle her iki katyonda, daralmış 2:1 kil mineralleri tabakalar arasında tutulmakta ve "fikse $\mathrm{K}^{+"}$ veya "fikse $\mathrm{NH}_{4}{ }^{+"}$ terimi kullanılagelmiştir. $\mathrm{NH}_{4}{ }^{+}$ve kristal tabakalardaki negatif yükler arasındaki elektrostatik enerji amonyumun hidrasyon enerjisinden büyüktür. $\mathrm{NH}_{4}{ }^{+}$iyonu hidrate su tabakasını boşaltmaya ve fiksasyonun gerçekleştiği kafes boşluğuna girmeye uygundur (Kittrick, 1966).

Nieder ve ark. (2011)'na göre topraklarda fikse $\mathrm{NH}_{4}{ }^{+}$ ve $\mathrm{NH}_{4}{ }^{+}$fiksasyonu, çelişen sonuçlarla birlikte bir takım araştırmaların konusu olagelmiştir. Sonuçlar metodoloji, toprak tipi, mineralojik kompozisyon ve agro-klimatik koşullar nedeniyle değişiklik göstermektedir. Farklı topraklarda doğal fikse amonyum içerikleri ana materyal, tekstür (Baethgen ve Alley, 1987), kil içeriği (Opuwaribu ve Odu, 1974; Sowden ve ark., 1978; Moyano ve Gallardo, 1988; Juang, 1990), kil mineral kompozisyonu (Feigin ve Yaalon,1974; Sparks ve ark., 1979; Doram ve Evans,1983; Niederbudde, 1983), toprak potasyum durumu ve 2:1 kil mineralleri tabakalar arasinın $\mathrm{K}$ doygunluğu (Hinman, 1966) ve nem koşullarına (Black ve Waring, 1972) göre farklılık göstermektedir.

Liu ve ark. (2008), uzun süreli bir potasyum gübrelemesi ve önemli miktarda illit kilinin oluşumu ile birlikte, amonyumun killerdeki tabakalar arası alanlarda ekstrakte-olmayan iyon olarak kolayca fikse olduğunu göstermişlerdir. Diğer bir deyişle illit minerali, yapıları içerisindeki susuz potasyum ile katyon değişimi yoluyla amonyum iyonlarını fikse etmeye oldukça uygun bir mineraldir. Amonyumun bu 
minerallerin içerisinden potasyumdan çok daha kolay ekstrakte edilebileceği düşünülmektedir.

\section{Amonyum Serbestlenmesi}

Amonyumun fiksasyonu ve serbestlenmesi, $\mathrm{NH}_{4}{ }^{+}$un değişebilir $\mathrm{NH}_{4}{ }^{+}$ve toprak çözeltisindeki $\mathrm{NH}_{4}{ }^{+}$ miktarları arasındaki kimyasal dengeye dayanmaktadır (Nommik ve Vahtras, 1982). Genel olarak toprağın fiksasyon kapasitesi arttıkça fikse $\mathrm{NH}_{4}{ }^{+}$'un elverişliliği azalmaktadır. Diğer yandan, fikse edilen $\mathrm{NH}_{4}{ }^{+}$' un elverişliliğinin montmorillonit ihtiva eden topraklarda en fazla ve verimiküllit ihtiva eden topraklarda ise en az olduğu ileri sürülmektedir (Allison ve ark., 1953).

Kil minerallerinin içerdiği $\mathrm{NH}_{4}{ }^{+}$genel olarak 2:1 kil mineralleri tabakaları arasında bulunmakta ve sıklıkla $\mathrm{K}^{+}$ile yer değişebilmektedir. Bu nedenle tabakalar arası $\mathrm{NH}_{4}{ }^{+}$aynı zamanda değişemez amonyum veya fikse olmuş amonyum olarak da adlandırılmaktadır. Bitki kökleri tarafından $\mathrm{NH}_{4}{ }^{+}$un kullanılabilirliği açısından, karşıt görüşler ve araştırmalar içeren veriler mevcuttur (Scherer, ve Mengel, 1986). Walsh ve Murdock (1963) ve bununla birlikte Martin ve ark. (1970) bu $\mathrm{NH}_{4}{ }^{+}$fraksiyonunun çok düşük oranda yarayışlı olduğunu bildirmişlerdir. Kowalenko ve Ross (1980) ve aynı zamanda van Praag ve ark. (1980), fikse $\mathrm{NH}_{4}^{+}$olarak isimlendirilen amonyumun kayda değer miktarlarda serbestlendiğini ve bu nedenle bitki beslemeyi önemli derecede desteklediğini bulmuşlardır. Scherer (1984), tabakalar arası $\mathrm{NH}_{4}{ }^{+} \mathrm{u},{ }^{15} \mathrm{~N}$ şeklinde işaretleyerek, tabakalar arası $\mathrm{NH}_{4}{ }^{+}$un serbestlenmesi ve Misterlich saksılarında büyüyen ürünlerin kaldırdığı $\mathrm{N}$ arasında yüksek derecede önemli korelasyon bulmuştur.

Amonyum fiksasyonu ve serbestlenmesi, toprak azot kaynağına özgü bitki azot alımına etkisinden dolayı (Nieder ve ark., 2011) azot gübresinin etkinliği açısından çok önemli bir rol oynamaktadır ( Scherer ve Mengel, 1986; Dou ve Steffens, 1995; Steffens ve Sparks, 1999; Juang ve ark., 2001). Yüksek $\mathrm{NH}_{4}{ }^{+}$ fiksasyonu kapasitesine sahip topraklarda $\mathrm{NH}_{4}{ }^{+}$un bir kısmı $\mathrm{NH}_{4}{ }^{+}$-teşkilli veya $\mathrm{NH}_{4}^{+}$-içeren gübrelerin kil mineralleri tabakaları arasına bağlanması yoluyla sağlanmaktadır (Nieder ve ark., 2011). Artan $\mathrm{NH}_{4}{ }^{+}$ fiksasyonu bitki geri kazanımı optimize etmek ve çevrede azot kayıplarını en aza indirmek amacıyla, $\mathrm{NH}_{4}{ }^{+}$iyonlarının kil mineralleri tabakaları arasına girdikten sonra nitrifikasyon işlemi ile dışarıya çıkması (Guo ve ark., 1983) şeklinde topraklarda yarayışlı azot havuzunu artırmanın bir yolu olabilir (Liu ve ark., 2008). Bu nedenle fikse edilmiş $\mathrm{NH}_{4}^{+}$ havuzu topraklarda $\mathrm{N}$ kayıplarını ve bitkiye yarayışlı mineral azotu etkileyen bir çeşit tampon görevi görmektedir (Nieder ve ark., 2011).

Kurak alanlarda buğdayda üst gübre uygulaması genellikle amonyum nitrat formunda iki uygulama şeklinde yapılmaktadır. İkinci uygulama aşaması kurak dönemlerde susuz koşullarda sorun olmaktadır. Yağışın olmadığı koşullarda ya uygulanmamakta, yada yağış gelir düşüncesi ile uygulandığında yeteri kadar fayda sağlanamamaktadır. Bu çalışmada da yukarıda verilen literatürlerden hareketle buğday tarımında kullanılan üst gübrenin amonyum ve üre formunda erken evrede tek seferde verilerek, hububatta pratikte uygulanan geç dönemdeki amonyum nitrat formunda ikinci üst gübre uygulamasina alternatif olarak, bitkinin azot yarayışlılığını arttırmak amaçlanmıştır. Bitkiye erken evrede amonyum ve üre formunda verilen azotun $2: 1$ tipi mineraller tarafindan fiksasyonu sağlanarak, kurak dönemde hububatın azot ihtiyacının, toprakta fikse edilen amonyum formunda karşlanıp karşılanmayacağı araştırılmıştır.

\section{MATERYAL ve METOT}

$\mathrm{Bu}$ çalışma, 2015/2016 ve 2016/2017 sezonlarında, KSÜ Ziraat Fakültesinin araştırma sahası olarak kullandığı deneme alanında yürütülmüştür. Araştırmada, Ceyhan-99 buğday çeşidi kullanılmıştır. Araştırmanın yapıldığı Kahramanmaraş ili konum itibariyle Türkiye'nin Doğu Akdeniz Bölgesinde, 37º $38^{\prime}$ kuzey paralelleri ve $36^{\circ} 37^{\prime}$ doğu meridyenleri arasında yer almaktadır ve rakımı 568 m'dir. Yörede Akdeniz iklimi hâkim olup, gece-gündüz arası sıcaklık farkı düşüktür. Kışları genellikle ılık ve yağışlı, yazları ise sıcak ve kuraktır. Çalışma alanına ait aylık ortalama yağış ve sıcaklık verileri Şekil 1 ve Şekil 2 de verilmiştir.

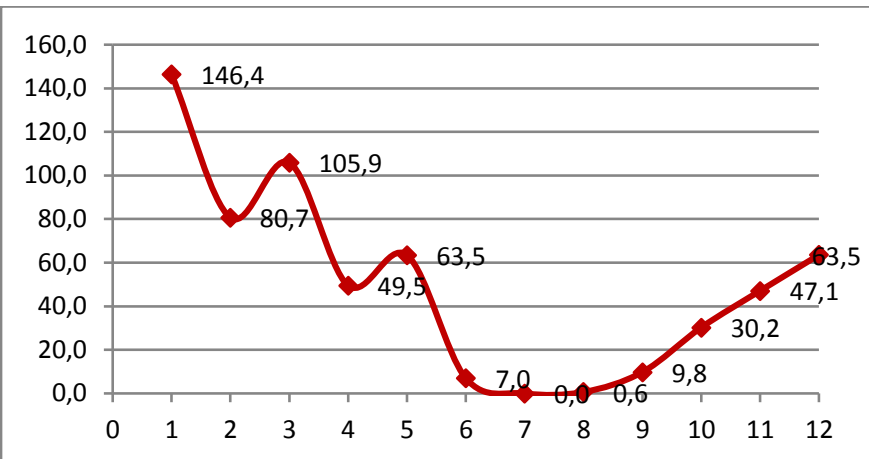

Şekil 1. 2014, 2015, 2016 Yılları Aylık Ortalama Yağış Değerler (MGM, 2018)

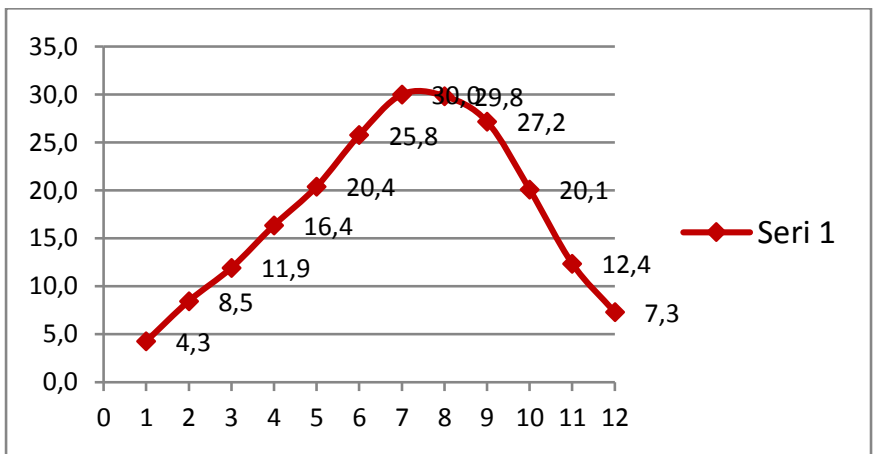

Şekil 2. 2014, 2015, 2016 Yılları Aylık Ortalama Sıcaklık Değerleri (MGM, 2018) 
Deneme tesadüf parselleri deneme desenine göre, üç tekerrürlü olacak şekilde $5 \times 6 \mathrm{~m}$ boyutlarında toplam 9 adet parselde kurulmuştur. Çalışmada üst gübre kontrol grubu (çiftçi uygulaması) kalsiyum amonyum nitrat (CAN) gübresi olarak iki aşamada uygulanmıştır. Alternatif uygulamalar ise üre (ÜRE) ve amonyum sülfat (AS) gübreleri olarak tek seferde yapilmıştır.

Bütün deneme parsellerine ekimle birlikte $30 \mathrm{~kg}$ 20:20:0 gübresi kullanılmıştır. Çiftçi uygulamasında dekara her seferinde (erken ilkbahar ve geç ilkbahar) $19.23 \mathrm{~kg}$ CAN olarak uygulanmıştır. Alternatif uygulamalarda ise $21.74 \mathrm{~kg} / \mathrm{da}$ üre ve $50 \mathrm{~kg} / \mathrm{da} A S$ gübreleri tek seferde uygulanmıştır. Deneme kurulumunda serpme ekim yöntemi uygulanmıştır.

Araştırma topraklarında bünye tayini Bouyoucos (1951)'un hidrometre metoduyla, $\mathrm{pH}$ tayini saturasyon çamurunda Black (1965)'ın bildirdiği şekilde, toplam tuz Richards (1954)'a, kireç analizi Gülçur (1974)'a ve organik madde tayini Nelson ve Sommers (1996)'ın yaş yakma metoduna göre gerçekleştirilmiştir. Değişebilir katyonlar Helmke ve Sparks (1996)'ın, mikro elementler DTPA yöntemiyle Lindsay ve Norvell (1978)'in ve yarayışlı fosfor Kuo (1996)'nun bildirdiği yöntemlerle belirlenmiştir. Buğday sap ve tanelerinde azot Khejldal metodu ile fosfor yaş yakma ile analize hazırlanan örneklerde UV-spektrofotometrede vanadomolibdofosforik asit ile diğer makro ve mikro elementler ise yaş yakma metodu ile analize hazırlanan örneklerde AAS 240 Agilent Atomik Absorbsiyon Spektrofotometresinde belirlenmiştir.

Araştırma alanına ait toprağın bazı fiziksel ve kimyasal özellikleri Çizelge 1'de verilmiştir. Çizelge 1'de görüldüğü gibi deneme alanı toprakları kumlukilli-tınlı (SCL) bünyeye sahiptir. Toprağın pH'sı 6.84 ile nötre yakın, kireç oranı ise \% 7.69 değeri ile orta kireçli, toplam tuzluluk oranı \% 0.17 ile hafif tuzlu ve organik madde oranının \% 1.35 ile düşük olduğu görülmektedir.

Çizelge 1. Deneme alanına ait toprağın bazı fiziksel ve kimyasal özellikleri

\begin{tabular}{|c|c|c|c|c|c|c|c|c|}
\hline $\mathrm{pH}$ & & Kum & Silt & & & Tuz & Kireç & $\mathrm{OM}$ \\
\hline & \multicolumn{8}{|c|}{$\%$} \\
\hline 6.84 & & 51.47 & 26.36 & & & 0.17 & 7.69 & 1.35 \\
\hline \multirow[t]{2}{*}{$\mathrm{N}$} & $\mathrm{P}$ & $\mathrm{K}$ & $\mathrm{Ca}$ & $\mathrm{Mg}$ & $\mathrm{Mn}$ & $\mathrm{Zn}$ & $\mathrm{Fe}$ & $\mathrm{Cu}$ \\
\hline & \multicolumn{8}{|c|}{ mgkg-1 $^{-1}$} \\
\hline 240 & 7 & 200 & 11100 & 620 & 7.1 & 0.2 & 5.8 & 0.9 \\
\hline
\end{tabular}

Çizelge 1'de belirtildiği üzere makro elementlerden toplam azot miktarı $240 \mathrm{mg} \mathrm{kg}^{-1}$, yarayışlı fosfor miktarı $7 \mathrm{mg} \mathrm{kg}^{-1}$, potasyum $200.0 \mathrm{mg} \mathrm{kg} \mathrm{m}^{-1}$, kalsiyum $11100 \mathrm{mg} \mathrm{kg}^{-1}$, magnezyum $620 \mathrm{mg} \mathrm{kg}{ }^{-1}$, mangan 7.1 $\mathrm{mg} \mathrm{kg}{ }^{-1}$, çinko $0.2 \mathrm{mg} \mathrm{kg}^{-1}$, bakır $0.9 \mathrm{mg} \mathrm{kg}^{-1}$ ve demir $5.8 \mathrm{~kg} \mathrm{mg}^{-1}$ olarak ölçülmüştür.

2 mm'lik elekten geçirilmiş toprak örneğindeki çimentolaştırıcı maddeler pH'sı 5 olan sodyum asetatasetik asit tampon çözeltisi ile; organik madde hidrojen peroksitle; serbest demir ve aliminyum oksitler sitrat-dithionit-bikarbonat ile ortamdan uzaklaştırılmıştır. Kum ıslak eleme ile; silt ise stokes yasasından yararlanılarak kil fraksiyonundan ayrılmıştır (Jackson, 1969). Örnekler K ve Mg iyonları ile doyurulup slaytlar hazırlanarak X-ışını kırınımları çekilmiştir. X-ışını kırınımlarındaki doruk alanları hesaplanıp minerallerin difrakte gücü hesaplanmıştır. Kantitatif kil analizinde, Yılmaz ve Sayın (1998)'ın Çukurova Bölgesi toprakları ve Yılmaz (1990)'ın Harran Ovası topraklarında elde ettikleri çarpım faktörü katsayıları (Smektit/Paligorskit:3.37, Smektit/Illit: 2.25, Smektit/Kaolinit:3.29 çarpım faktörleri kullanılmıştır) kullanılarak hesaplanmıştır. Deneme alanı toprağının $\mathrm{K}^{+}$ve $\mathrm{Mg}^{++}$için XRD analizi sonuçları Şekil 3 ve Şekil 4'de verilmiştir. Şekil 3 incelendiğinde smektit ve vermikülitin baskın düzeyde olduğu, paligorskit, illit ve kaolinit doruklarının varlığı X-ışını difraktogramlarında görülmüştür. Potasyum ile doyurulan slaytın X-ışını difraktogramı incelendiğinde magnezyum doygunluğunda 14-15 $\mathrm{A}^{0}$ da doruk veren vermikülitin, potasyum doygunluğunda $10 \mathrm{~A}^{0}$ doruğunda bir artışa neden olduğu gözlenmiştir.

Çizelge 2'deki verilere göre deneme alanı toprağı smektit kil mineralince baskın olduğu sonucuna ulaşılmaktadır. Smektit kil minerali \% 68.2 ve bunu takiben Paligoskit \% 13.07 değerine sahiptir. Dama (2009) da yaptığı çalışmada Kahramanmaraş topraklarını smektit mineralince zengin olduğunu tespit etmiştir.

Tesadüf parselleri deneme planına göre yürütülmüş olan denemeden rutin kimyasal analizler ve fiziksel ölçümlerle elde edilen tüm veriler SPSS programı (IBM SPSS Advanced Statistics version 20.0.0) kullanılarak varyans analizleri ve Duncan çoklu karşılaştırma testleri ile değerlendirilmiştir (Hays, 1988).

Çizelge 2 . Deneme Alanı Toprağının Kil Bileşeni Oranları

\begin{tabular}{llllll}
\hline Kil Bileşenleri & Smektit & Paligorskit & Kaolinit & Vermikülit & İlit \\
\hline Oranlar (\%) & 68.2 & 13.07 & 8.37 & 5.37 & 4.95 \\
\hline
\end{tabular}




\section{BULGULAR ve TARTIŞMA}

Farklı gübre uygulamalarının buğdayın fiziksel özellikleri üzerine etkileri incelendiğinde bin dane ağırlığında istatistiksel açıdan önemli farklılıklar

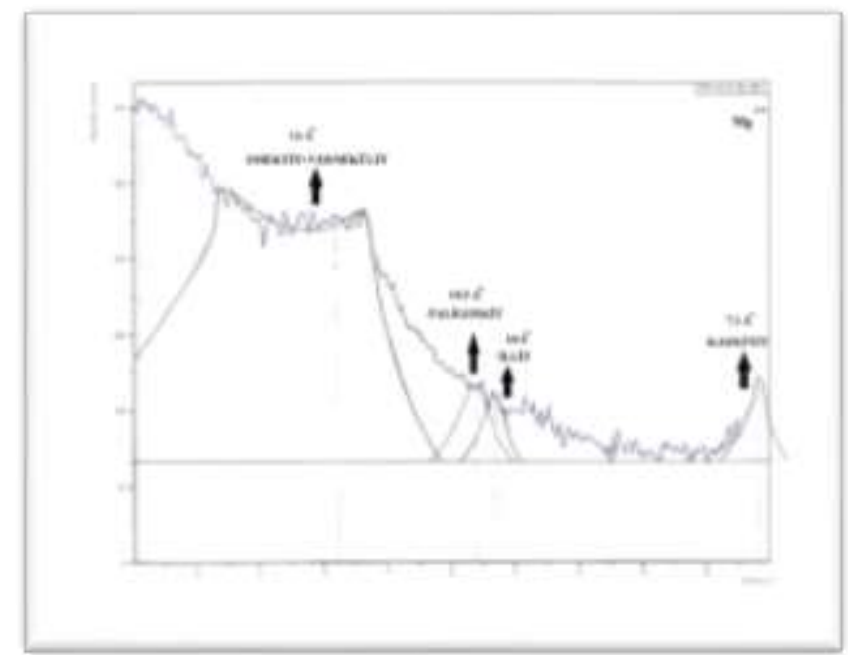

Şekil 3.Mg Doygunluğunda XRD analiz sonucu görülmüştür. Üre ve AS uygulanan buğday bitkilerinin (363 $\mathrm{kgda}^{-1}, 353 \mathrm{kgda}^{-1}$ ) CAN gübresi uygulanan bitkilere (311 $\left.\mathrm{kgda}^{-1}\right)$ kıyasla daha yüksek verim verdiği görülmüştür (Çizelge 3).

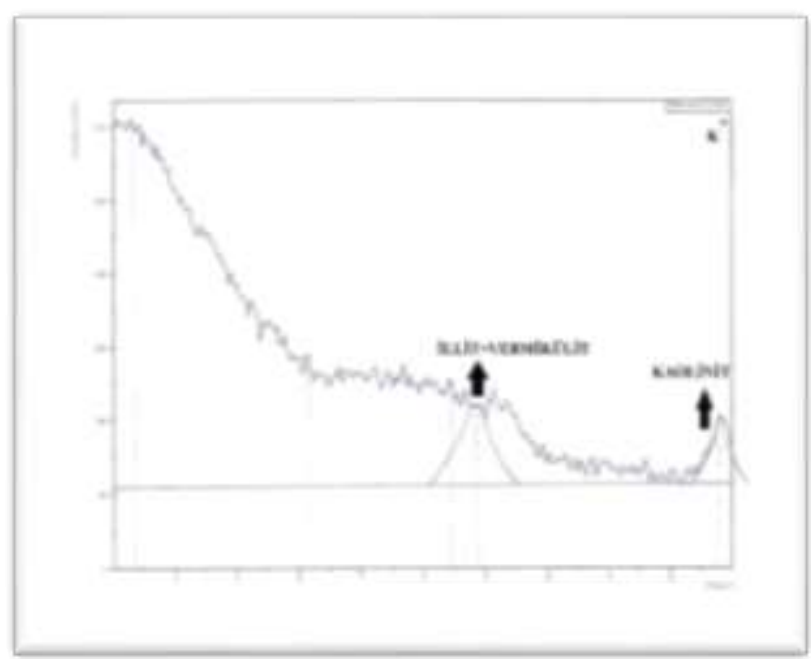

Şekil 4.K Doygunluğunda XRD analiz sonucu

Çizelge 3. Farklı gübre uygulamalarının buğdayın agronomik özellikleri üzerine etkilerinin çoklu karşılaştırması (Duncan Testi)

\begin{tabular}{|c|c|c|c|c|c|}
\hline Gübre & $\begin{array}{l}\text { Verim } \\
(\mathrm{kg} / \mathrm{da})\end{array}$ & $\begin{array}{l}\text { Bin Tane } \\
\text { Ağırlığı (g) }\end{array}$ & $\begin{array}{l}\text { Bitki Boyu } \\
\text { (cm) }\end{array}$ & $\begin{array}{l}\text { Başak Sayısı } \\
\text { (adet) }\end{array}$ & $\begin{array}{l}\text { Başak Boyu } \\
\text { (cm) }\end{array}$ \\
\hline & $\begin{array}{l}\text { 1.Yil/2.Y1l } \\
\text { Ort* }\end{array}$ & $\begin{array}{l}\text { 1.Y1l/2.Yll } \\
\text { Ort* }\end{array}$ & $\begin{array}{l}\text { 1.Yll/2.Yıl } \\
\text { Ort* }\end{array}$ & $\begin{array}{l}\text { 1.Yll/2.Yll } \\
\text { Ort* }\end{array}$ & $\begin{array}{l}\text { 1.Yll/2.Yll } \\
\text { Ort* }\end{array}$ \\
\hline & $276 / 346$ & $27.2 / 37.4$ & $54.3 / 77.8$ & $372 / 433$ & $7.2 / 7.4$ \\
\hline \multirow[t]{2}{*}{ CAN } & $311 \mathrm{~b}$ & $32.3 \mathrm{c}$ & $66.1 \mathrm{~b}$ & $402.5 \mathbf{a}$ & $7.3 \mathrm{ab}$ \\
\hline & $269 / 458$ & $29.3 / 37.8$ & $55.8 / 83.3$ & $384 / 460$ & $7.7 / 7.4$ \\
\hline \multirow[t]{2}{*}{ ÜRE } & $363 \mathbf{a}$ & $33.6 \mathrm{~b}$ & $69.6 \mathbf{a}$ & $422 \mathbf{a}$ & $7.5 \mathbf{a}$ \\
\hline & $267 / 440$ & $32.9 / 37.7$ & $51.9 / 78.9$ & $359 / 354$ & $6.7 / 7.5$ \\
\hline AS & $353 \mathbf{a}$ & $35.3 \mathbf{a}$ & $65.4 \mathrm{~b}$ & $356.5 \mathrm{~b}$ & $7.1 \mathrm{~b}$ \\
\hline
\end{tabular}

*Ort : Birinci ve ikinci yıl verilerinin ortalama değerleri.

Bin tane ağırlıkları açısından bakıldığında AS uygulanan bitkilerin (35.3 g), ÜRE uygulanan bitkilerden (33.6 g), ÜRE uygulanan bitkilerin ise CAN uygulanan bitkilerden (32.3 g) istatistiki olarak önemli ve daha yüksek olduğu gözlemlenmiştir. Bitki boyları açısından ÜRE uygulanan bitkilerin $(69.6 \mathrm{~cm})$ CAN ve AS uygulanan bitkilere $(66.1 \mathrm{~cm}, 65.4 \mathrm{~cm})$ göre daha yüksek değerlere sahip olduğu belirlenmiştir. Başak sayıları açısından CAN ve ÜRE uygulanan parsellerde başak sayıları (402.5 adet $/ \mathrm{m}^{2}, 422$ adet $\left./ \mathrm{m}^{2}\right)$ AS uygulanan parsellere $\left(356.5\right.$ adet $\left./ \mathrm{m}^{2}\right)$ kiyasla daha fazla ölçülmüştür. Başak boyları incelendiğinde ise ÜRE uygulamalarının $(7.5 \mathrm{~cm})$ istatistiksel olarak CAN uygulamaları $(7.3 \mathrm{~cm})$ ile benzer ve AS uygulamalarına $(7.1 \mathrm{~cm})$ kiyasla daha etkili olduğu gözlenmektedir (Çizelge 3). Benzer çalışmalarda da (Kowalenko ve Ross,1980; van Praag ve ark.,1980), fikse $\mathrm{NH}_{4}{ }^{+}$olarak isimlendirilen amonyumun önemli oranda serbestlendiğini ve bu nedenle bitki beslemeyi önemli derecede desteklediğini bildirmektedirler.
Parametreler incelendiğinde de erken evrede verilen ÜRE ve AS'ın verim üzerine klasik uygulamaya kıyasla (CAN) istatistiki olarak önemli olduğu görülmektedir. Liu ve ark. (2008)'na göre yüksek tabaka yüküne sahip smektitler gibi 2:1 killerin stabilizasyonu potasyum ve amonyumun gübreleme ajanlarını korumak anlamında kararlı bir adımı teşkil etmektedir. Velde ve Barre (2010) de bitkilerin gerektiğinde bir çok elementin killerden temin edilebileceğini, çeşitli sebeplerle bitkiler bu elementleri sağlayamadığında, killerdeki stokların bazı büyüme evrelerinde kullanılabileceğini belirtmişlerdir. Nieder ve ark. (2011)'a göre de fikse amonyumun serbestlenmesini içeren topraktan azot katılımı, uygulanan azotun geri kazanım etkinliğini büyük ölçüde değiştirmektedir, çünkü toprak azotu büyük oranda gübre azotunun yerini almaktadır. $\mathrm{Bu}$ durumun, yani genişleyebilir killerde fikse olma kapasitesine sahip olan amonyumun ÜRE ve AS kullanılan parsellerdeki verim artışının nedeni 
olabileceği düşünülmektedir.

Farklı üst gübre uygulamalarının buğday bitkisi saplarının makro ve mikro element içerikleri üzerine etkileri incelendiğinde, azot düzeyleri istatistikî olarak CAN, Üre ve AS uygulanan bitkilerde (\%0.40, \%0.47, $\% 0.36$,sırasıyla) benzer olarak bulunmuştur. Benzer sekilde fosfor $(\% 0.07, \% 0.06, \% 0.06)$, potasyum $(\% 0.80$, $\% 0.78, \% 0.86)$, kalsiyum (\%0.19, \%0.17, \%0.18), magnezyum (\%0.05, \%0.05, \%0.05), demir (99.0, 105.1, $\left.103.1 \mathrm{mg} \mathrm{kg}^{-1}\right)$ ve bakır (6.4, 6.6, $\left.6.7 \mathrm{mg} \mathrm{kg}^{-1}\right)$ konsantrasyonları arasında da istatistiki olarak önemli bir fark bulunmamıştır. Diğer yandan çinko konsantrasyonları incelendiğinde ÜRE ve AS uygulanan bitkilerde (10.5 mg kg-1, $11.3 \mathrm{mg} \mathrm{kg-1)}$ CAN gübresi uygulanan bitkilere (10.2 mg kg-1), kıyasla istatistiki olarak daha yüksek değerler elde edilmiştir. Mangan konsantrasyonları bakımından ise
CAN uygulanan bitkilerde (24.1 $\left.\mathrm{mg}^{\mathrm{kg}}{ }^{-1}\right)$ ÜRE uygulamaları $\left(22.4 \quad \mathrm{mg} \quad \mathrm{kg}^{-1}\right)$ ile benzer AS uygulamalarına (20.5 $\left.\mathrm{mg} \mathrm{kg}^{-1}\right)$ kıyasla yüksek değerler elde edilmiştir (Çizelge 4). Lavkor (2006) yaptığ çalışmada saptaki makro element içerikleri bakımından en düşük ve en yüksek değerler azot için $\%$ 2.58-3.38, fosfor için \% 0.19-0.33 ve potasyum için \% 1.30-2.82 aralığında yer almıştır. Bu çalışmadaki azot, fosfor ve potasyum verileri bu değerlerden daha düşük tespit edilmiştir. Aynı çalışmada saptaki mikro element içerikleri bakımından en düşük ve en yüksek değerler demir için 59.1-200.8 mg/kg, mangan için $35.5-58.4 \mathrm{mg} / \mathrm{kg}$, çinko için $11.8-23.5 \mathrm{mg} / \mathrm{kg}$ ve bakır için $2.5-6.7 \mathrm{mg} / \mathrm{kg}$ aralığında yer almıştır. Çalışmadaki verilere göre demir, bakır ve çinko konsantrasyonları benzerlik gösterirken, mangan konsantrasyonu görece düşük tespit edilmiştir.

Çizelge 4. Farklı gübre uygulamalarının buğday saplarının makro ve mikro element konsantrasyonları üzerine etkilerinin çoklu karşılaştırması (Duncan Testi)

\begin{tabular}{|c|c|c|c|c|c|}
\hline Gübre & $\mathrm{N}$ & $\mathbf{P}$ & $\mathrm{K}$ & $\mathrm{Ca}$ & $\mathrm{Mg}$ \\
\hline \multicolumn{6}{|c|}{$\%$} \\
\hline & $\begin{array}{l}\text { 1.Yll/2.Yll } \\
\text { Ort* }\end{array}$ & $\begin{array}{l}\text { 1.Yll/2.Yll } \\
\text { Ort* }\end{array}$ & $\begin{array}{l}\text { 1.Yll/2.Yll } \\
\text { Ort* }\end{array}$ & $\begin{array}{l}\text { 1.Yll/2.Yll } \\
\text { Ort* }\end{array}$ & $\begin{array}{l}\text { 1.Yll/2.Yll } \\
\text { Ort* }\end{array}$ \\
\hline \multirow{3}{*}{ CAN } & $030 / 0.49$ & $0.02 / 0.12$ & $0.55 / 1.05$ & $0.16 / 0.22$ & $0.03 / 0.06$ \\
\hline & 0.40 & 0.07 & 0.80 & 0.19 & 0.05 \\
\hline & $0.47 / 0.46$ & $0.02 / 0.11$ & $0.60 / 0.96$ & $0.16 / 0.18$ & $0.04 / 0.06$ \\
\hline \multirow[t]{2}{*}{ ÜRE } & 0.47 & 0.06 & 0.78 & 0.17 & 0.05 \\
\hline & $0.29 / 0.43$ & $0.02 / 0.10$ & $0.61 / 1.10$ & $0.17 / 0.18$ & $0.04 / 0.05$ \\
\hline \multirow[t]{3}{*}{ AS } & 0.36 & 0.06 & 0.86 & 0.18 & 0.05 \\
\hline & $\mathrm{Fe}$ & $\mathrm{Zn}$ & $\mathrm{Cu}$ & $\mathrm{Mn}$ & \\
\hline & \multicolumn{5}{|c|}{$\mathrm{mg} \mathrm{kg}^{-1}$} \\
\hline \multirow[t]{2}{*}{ CAN } & $89.7 / 108.3$ & $4.2 / 16.3$ & $1.4 / 11.3$ & $26.9 / 21.3$ & \\
\hline & 99.0 & $10.2 \mathrm{~b}$ & 6.4 & $24.1 \mathrm{a}$ & \\
\hline \multirow[t]{2}{*}{ ÜRE } & $101.9 / 108.2$ & $6.3 / 14.7$ & $1.8 / 11.3$ & $27.4 / 17.5$ & \\
\hline & 105.1 & $10.5 \mathrm{a}$ & 6.6 & $22.4 \mathrm{ab}$ & \\
\hline \multirow[t]{2}{*}{ AS } & $115.4 / 90.7$ & $6.4 / 16.2$ & $2.4 / 11.0$ & $28.5 / 12.5$ & \\
\hline & 103.1 & $11.3 \mathrm{a}$ & 6.7 & $20.5 \mathrm{~b}$ & \\
\hline
\end{tabular}

*Ort : Birinci ve ikinci yıl verilerinin ortalama değerleri.

Farklı üst gübre uygulamalarının buğday bitkisi tanelerinin makro ve mikro element içeriği üzerine etkileri incelendiğinde, azot düzeyleri istatistikî olarak CAN, ÜRE ve AS uygulanan bitkilerde (\%2.09, \%2.19, \%2.06) benzer olarak belirlenmiştir. Yine benzer şekilde fosfor $(\% 0.15, \% 0.14, \% 0.14)$, potasyum $(\% 0.28$, $\% 0.28$, \%0.30), kalsiyum $(\% 0.16, \% 0.15, \% 0.15)$, magnezyum (\%0.08, \%0.08, \%0.08), demir (64.6, 79.2, $87.1 \mathrm{mg} \mathrm{kg}^{-1}$ ), çinko (22.85, 24.7, $24.4 \mathrm{mg} \mathrm{kg}^{-1}$ ), bakır $\left(3.5,3.4,3.5 \mathrm{mg} \mathrm{kg}^{-1}\right)$ ve mangan $(30.1,29.3,30.8 \mathrm{mg}$ $\left.\mathrm{kg}^{-1}\right)$ konsantrasyonları arasında da istatistiki olarak önemli bir fark bulunmamıştır (Çizelge 5). Adiloğlu (1989) yaptığı çalışmada tanedeki makro elementlerden azot \% 2.04-3.30, fosfor \% 0.15-0.23, potasyum \% 2.15-3.63, kalsiyum \% 1.97-2.45, magnezyum \% 0.48-1.42 aralığında yer almıştır. Bu çalışmadaki veriler kıyaslandığında potasyum, kalsiyum ve magnezyum konsantrasyonları düşük ölçülürken, azot ve fosfor miktarları benzer konsantrasyonlarda belirlenmiştir. Uçar (2016) yaptığı çalışmada tanedeki mikro element içeriği bakımından en düşük ve en yüksek değerler bakır için $0.25-19.15 \mathrm{mg} / \mathrm{kg}$, mangan için $12.25-47.45 \mathrm{mg} / \mathrm{kg}$, demir için $0.75-48.95 \mathrm{mg} / \mathrm{kg}$, çinko için 2.75-31.75 $\mathrm{mg} / \mathrm{kg}$ aralığında yer almıştır. Çinko, bakır ve mangan konsantrasyonları benzerlik gösterirken, demir konsantrasyonları görece yüksek tespit edilmiştir.

\section{SONUÇ}

Yapılan araştırma sonucunda, smektit ve vermikülit killerinin baskın olduğu kurak alanlarda buğday yetiştiriciliğinde azotlu gübrelerin amonyum ve üre formunda tek seferde verilmesinin uygun olduğu görülmüştür. 
Çizelge 5. Farklı gübre uygulamalarının buğday tanesinin makro ve mikro element konsantrasyonları üzerine etkilerinin çoklu karşılaştırması (Duncan Testi)

\begin{tabular}{|c|c|c|c|c|c|}
\hline Gübre & $\mathrm{N}$ & $\mathbf{P}$ & $\mathrm{K}$ & $\mathrm{Ca}$ & $\mathrm{Mg}$ \\
\hline \multicolumn{6}{|c|}{$\%$} \\
\hline & $\begin{array}{l}\text { 1.Yil/2.Yil } \\
\text { Ort* }\end{array}$ & $\begin{array}{l}\text { 1.Y1l/2.Yil } \\
\text { Ort* }\end{array}$ & $\begin{array}{l}\text { 1.Yil/2.Yll } \\
\text { Ort* }\end{array}$ & $\begin{array}{l}\text { 1.Y1l/2.Yil } \\
\text { Ort* }\end{array}$ & $\begin{array}{l}\text { 1.Yil/2.Yil } \\
\text { Ort* }\end{array}$ \\
\hline \multirow{2}{*}{ CAN } & $2.25 / 1.93$ & $0.20 / 0.10$ & $0.25 / 0.31$ & $0.04 / 0.27$ & $0.07 / 0.09$ \\
\hline & 2.09 & 0.15 & 0.28 & 0.16 & 0.08 \\
\hline \multirow{3}{*}{ ÜRE } & $2.50 / 1.88$ & $0.20 / 0.08$ & $0.26 / 0.30$ & $0.04 / 0.25$ & $0.08 / 0.09$ \\
\hline & 2.19 & 0.14 & 0.28 & 0.15 & 0.08 \\
\hline & $2.18 / 1.94$ & $0.20 / 0.08$ & $0.26 / 0.33$ & $0.04 / 0.25$ & $0.08 / 0.09$ \\
\hline \multirow[t]{3}{*}{$\mathrm{AS}$} & 2.06 & 0.14 & 0.30 & 0.15 & 0.08 \\
\hline & $\mathrm{Fe}$ & $\mathrm{Zn}$ & $\mathrm{Cu}$ & Mn & \\
\hline & \multicolumn{5}{|c|}{$\mathrm{mg} \mathrm{kg}^{-1}$} \\
\hline \multirow[t]{2}{*}{ CAN } & $81.5 / 47.7$ & $17.2 / 28.5$ & $2.8 / 4.3$ & $26.2 / 34.0$ & \\
\hline & 64.6 & 22.85 & 3.5 & 30.1 & \\
\hline \multirow[t]{2}{*}{ ÜRE } & $101.9 / 56.5$ & $19.2 / 30.2$ & $2.9 / 3.8$ & $26.6 / 32.0$ & \\
\hline & 79.2 & 24.7 & 3.4 & 29.3 & \\
\hline \multirow[t]{2}{*}{ AS } & $107.9 / 66.3$ & $19.7 / 29.2$ & $3.1 / 4.0$ & $26.9 / 34.7$ & \\
\hline & 87.1 & 24.4 & 3.5 & 30.8 & \\
\hline
\end{tabular}

*Ort : Birinci ve ikinci yıl verilerinin ortalama değerleri.

Bunun, amonyum iyonunun 2:1 kil mineralleri içerisindeki bazal oksijen düzlemindeki ditrigonal yuvalara tam olarak uyum göstermesi ile ilişkili olarak tabakalar arasında yüksek fiksasyon oranlarına ulaşmasından kaynaklandığı düşünülmektedir.

Amonyum iyonunun tabakalar arasında bu şekilde fikse edilmesi kil minerallerin bir tür depo görevi gördüğü şeklinde algılanabilir. Bu aşamadan sonra fikse edilen amonyumların yeniden serbestlenmesi ile birlikte, toprak çözeltisine geçişi ve bitki tarafından alımının gerçekleştiği düşünülmektedir. Bu şekilde killerdeki stok edilen amonyumlar bazı büyüme evrelerinde kullanılabilmektedir. Birçok araştırmacı tarafindan fikse $\mathrm{NH}_{4}{ }^{+}$olarak isimlendirilen bu amonyumun kayda değer miktarlarda serbestlendiği ve bu nedenle bitki beslemeyi önemli derecede desteklediğini savunulmaktadır.

Toprağa verilen ve fikse olan azotun sonraki süreçlerde defiksasyonunu ile toprak çözeltisine katılımı, azotun geri kazanım etkinliğini artırabilmekte ve büyük ölçüde gübre azotu gibi davranmaktadır. Kimyasal gübre maliyetleri ile birlikte daha az girdiyle daha fazla gida üretimi yanında, özellikle de toprak ve su sisteminin kirlenmesini önleme odaklı çevresel yaklaşımlar toprak kökenli azot kaynaklarının kullanımına öncelik vermektedir.

Sonuç olarak, çiftçilerin uyguladığı ikinci üst gübre dozuna göre daha erken dönemde üst gübrenin tamaminın tek seferde üre veya amonyum formunda toprağa verilmesinin, geç dönemde ikiye bölünerek amonyum nitrat azotu formunda verilmesinden daha etkili olduğu, azotlu gübrelerin smektit ve vermikülitce baskın topraklarda üre ve amonyum formunda erken dönemde tek seferde verilmesinin hem maliyet bakımından hem de geç dönemde kuraklık nedeniyle oluşacak azot kayıpları riskini önlemek bakımından daha yararlı olacağı görülmüştür.

\section{KAYNAKLAR}

Adiloğlu A 1989. Trakya Bölgesi Asit Topraklarına Kireç İlavesinin Bazı Makro Besin Elementlerinin Elverişliliğine Etkisi Üzerinde Bir Araştırma. Trakya Üniversitesi Fen Bilimleri Enstitüsü Toprak Ana Bilim Dalı, Yüksek Lisans Tezi.. Tekirdağ, s. 20.

Allison FE, Doetsch JH, Roller EM 1951. Ammonium fixation and availability in Harpster clay loam. Soil Sci. 72:181-200.

Allison FE, Doetsch JH, Roller EM, 1953. Availability of fixed ammonium in soils containing different clay minerals. Soil Sci. 75:373-381.

Axley JH, Legg JO, 1960. Ammonium fixation in soils and the influence of potassium on nitrogen availability from nitrate and ammonium sources. Soil Sci. 90:151-156.

Baethgen WE, Alley MM 1987. Non-exchangeable ammonium nitrogen contribution to plant available nitrogen. Soil Sci Soc Am J 51:110-115.

Black CA 1965. Methods of Analysis Agreon., No: 9, Ame. Soc. Agr., MadisonWisconsin. USA.

Black AS, Waring SA 1972. Ammonium fixation and availability in some cereal producing soils of Queensland. Aust. J. Soil Res. 10:197-207

Bouyoucus GJ 1951. A Recalibration of The Hydrometer For Making Mechanical Analysis of Soils, Argon. Jour., 43:434-438.

Dama AY 2009. Farklı Kil Minerali İçeriğine Sahip 
Topraklarda Yetiştirilen Ispanak Bitkisinin Gelişimine Bazalt Tüfünün Etkisi. Kahramanmaraş Sütçü İmam Üniv. Fen Bilimleri Enstitüsü Toprak Ana Bilim Dalı, (Yüksek Lisans Tezi). Kahramanmaraş, 79 Sy.

Doram DR, Evans LJ 1983. Native fixed ammonium and fixation of added ammonium in relation to clay mineralogy in some Ontario soils. Can J Soil Sci. 63:631-639

Dou H, Steffens D 1995. Recovery of $15 \mathrm{~N}$ labelled urea as affected by fixation of ammonium by clay minerals. Z Pflanzenernahr Bodenkd 158:351-354

Feigin A, Yaalon DH, 1974. Non-exchangeable ammonium in soils of Israel and its relation to clay and parent material. J .Soil Sci. 25:384-397.

Frye WW, Hutcheson TB 1981. Release of $\mathrm{NH}_{4}{ }^{+}$in soils by oven drying. Soil Sci. Soc. Am. J.45:889892.

Guo PC, Bogring J, Scherer HW 1983. Verhalten von Dünger-NH4+ in Böden unterschiedlicher tonmineralischer Zusammensetzung. Z Z Pflanzenernahr Bodenkd 146:752-757.

Gülçur F 1974. Toprağın Fiziksel ve Kimyasal Analiz Metodları, İstanbul Üniversitesi Orman Fakültesi Yayınları, İ. Ü. Yayın No: 1970, Yayın No: 201, Kutulmuş Matbaası, İstanbul.

Hays LW 1988. Statistics, Holt Rinehart and Winston, Inc., London, Fourth Edition, P-544.

Helmke PA, Sparks DL 1996. Lithium, Sodium, Potassium, Rubidium, and Calcium, in Sparks,D.L., (Ed) Methods of Soil Analysis, Part 3, Chemical Methods, SSSA Book Series Number 5, SSSA., Madison,WI, s. 551-574.

Hinman WC 1966. Ammonium fixation in relation to exchangeable $\mathrm{K}$ and organic matter content in two Saskatchewan soils. Can J. Soil Sci. 46:223-225.

Jackson ML 1969. Soil Chemical Analysis, Advanced Course, $2^{\text {nd }}$ ed. Published by The Author, University of Wisconsin, Madison, 8955.

Juang TC 1990. Ammonium fixation as affected by temperature and drying-wetting effect in Taiwan soils. Proc Natl Sci Counc Repub China Part B Life Sci. 14:151-158.

Juang TC, Wang MK, Chen HJ, Tan CC 2001. Ammonium fixation by surface soils and clays. Soil Sci. 166:345-352.

Kittrick JA 1966. Forces involved in ion fixation by vermiculite. Soil Sci. Soc. Am. Proc. 30:801-803.

Kowalenko GG, Ross GJ 1980. Studies on the dynamics of 'recently' clayfixed NH] using ISN. Can. J. Soil Sci. 60 (1):61-70.

Kudeyarov VN 1981. Mobility of fixed ammonium in soil. In: Clark FE, Rosswall T (eds) Terrestrial nitrogen cycles. Ecol Bull (Stockholm) 33:281-290.

Kuo S 1996. Phosphorus in D.L. Sparks (Ed) Methods of Soil Analysis, Part 3, Chemical Methods, SSSA Book Series Number 5, SSSA., Madison,WI, s. 869921.
Lavkor I 2006. Osmaniye İli ve Çevresinde Bulunan Farklı Ana Materyaller Üzerinde Oluşan Topraklarda, Toprak Verimliliği-Bitki Besleme İlişkilerinin Belirlenmesi. Çukurova Üniversitesi Fen Bilimleri Enstitüsü Toprak Ana Bilim Dalı Yüksek Lisans Tezi. Adana, s. 44-51.

Liu YL, Zhang B, Li CL, Hu F, Velde B 2008. Longterm fertilization influences on clay mineral composition and ammonium adsorption in rice paddy soils. Soil Sci. Soc. Am. J. 72:1580-1590.

Lindsay WL, Norvel WA 1978. Development of DTPA soil test for $\mathrm{Zn}, \mathrm{Fe}, \mathrm{Mn}$ and $\mathrm{Cu}$. Soil Sci. Amer. J. 42 (3):421-28.

Lu CY, Zhang XD, Chen X, Shi Y, Ma J, Zhao MQ 2010. Fixation of labelled $\left({ }^{15} \mathrm{NH}_{4}\right)_{2} \mathrm{SO}_{4}$ and its subsequent release in black soil of Northeast China over consecutive crop cultivation. Soil Tillage Res. 106:329-334.

Lutz JA 1966. Ammonium and potassium fixation and release in selected soils of southeastern United States. Soil Sci. 102:366-372.

Martin AE, Gilkes RJ, Skjemstad JO 1970. Fixed ammonium in soils developed on some Queensland phyllites and its relation to weathering. Aust. J. Soil Res. 8:71-80.

Mengel K, Scherer HW 1981. Release of nonexchangeable (fixed) soil ammonium under field conditions during the growing season. Soil Sci. 131:226-232.

MGM 2018. Kahramanmaraş Meteoroloji İ Müdürlüğü aylık ortalama yağış ve sıcaklık verileri, 2018.

Moyano A, Gallardo JF 1988. Fixed ammonium determination in some clay soils. Commun. Soil Sci.Plant Anal 19:225-238.

Nieder R, Benbi DK, Scherer HW 2011. Fixation and defixation of ammonium in soils: A review. Biol. Fertil. Soils 47:1-14.

Niederbudde EA 1983. Das Tonmineral $-\mathrm{NH}_{4}{ }^{+}$, seine Stellung $\mathrm{zu}$ anderen N-Bindungsformen sowie seine Bewertung für NImmobilisierung und Mobilisierung in Böden. Kali-Briefe (Büntehof) 16:365-378.

Nelson DW, Sommers LE 1996. Total Carbon, Organic Carbon, and Organic Matter. In D.L. Sparks (Ed) Methods of Soil Analysis, Part 3, Chemical Methods, SSSA Book Series Number 5, SSSA., Madison,WI, s. 961-1011.

Nommik H 1965. Ammonium fixation and other reactions involving non-enzymatic immobilization of mineral nitrogen in soils. In: Bartholomew WV, Clark FE (eds), Soil nitrogen. Monograph, American Society of Agronomy 10:198-258.

Nommik H 1981. Fixation and biological availability of ammonium in soil clay minerals. Ecol. Bull. (Stockholm) 33:273-279.

Nommik H, Vahtras K 1982. Retention and fixation of ammonium and ammonia in soils. In: Stevenson FJ 
(ed.) Nitrogen in agricultural soils. Agronomy 22:123-171.

Opuwaribo E, Odu CTI 1974. Fixed ammonium in Nigerian soils I. Selection of a method and amounts of native fixed ammonium. J. Soil Sci. 25:256-264.

Osborne GJ 1976. The extraction and definition of nonexchangeable or fixed ammonium in some soils from southern New South Wales. Aust J Soil Res 14:373-380

SSJA 1984. Glossary of soil science terms. Soil Sci Soc Am, Madison, Wisconsin.

Page JB, Baver LO 1939. Ionic size in relation to fixation of cations by colloidal clay. Soil Sci. Soc. Amer. Proc. 4: 150-155.

Preston CM 1982. The availability of residual fertilizer nitrogen immobilized as clay-fixed ammonium and organic nitrogen. Can. J. Soil Sci. 62:479-486.

Sağlam MT 1974. Erzurum, Hasankale ve Erzincan Ovası topraklarında amonyum fiksasyonu, amonyum fiksasyonu ile potasyum araarasındaki bazı ilişkiler, mineralize olan nitrojen ve nitrojen kayıpları üzerine bir araştırma. Atatürk Üniversitezi, Ziraat Fakültesi (Basılmamış), Erzurum.

Scherer HW 1984. Beziehung zwischen dem Stickstoff-Entzug der Pflanzen und der Abnahme von spezifisch gebundenem NH4-N im Boden. Z. Pflanzenern thr Bodenk 147:29-36.

Scherer HW 1993. Dynamics and availability of the nonexchangeable $\mathrm{NH}_{4}{ }^{+}-\mathrm{N}$. A review. Eur. J. Agron. $2: 149-160$.

Scherer HW 1987. Zur Verfügbarkeit von Zwischenschicht- Ammonium der Tonminerale. Landwirtsch Forsch 40:259-276.

Scherer HW, Mengel K 1986. Importance of soil type on the release of nonexchangeable $\mathrm{NH}_{4}{ }^{+}$and availability of fertilizer $\mathrm{NH} 4+$ and fertilizer $\mathrm{NO}_{3}$. Fertil. Res. 8:249-258.

Sowden FJ, Maclean AA, Ross GJ 1978. Native clay fixed ammonium content and the fixation of added ammonium of some soils of Eastern Canada. Can, J. Soil Sci. 58:27-38.
Sparks DL, Blevins RL, Bailey HH, Barnhisel RI 1979. Relationship of ammonium nitrogen distribution to mineralogy in a Hapludalf soil. Soil Sci Soc Am J 43:786-789.

Steffens D, Sparks DL 1999. Effect of residence time on the kinetics of nonexchangeable ammonium release from illite and vermiculite. J. Plant Nutr. Soil Sci. 162:599-604.

Sucha V, Elsass F, Eberl D, Kuchta L, Madejova J, Gate W, Komadel P 1998.Hydrothermal synthesis of ammonium illite. Ame Miner 83: 58-67.

Sucha V, Sirahova V 1991. Potassium and ammonium fixation in smectites by wetting and drying clays. Clay Miner 39: 556-559.

Walsh LM, Murdock JT 1963. Recovery of fixed ammonium by corn in greenhouse studies. Soil Sci. Soc. Am. Proc. 27,200-20.

Uçar R 2016. Bingöl İlinden Toplanmış Yerel Kışlık Ekmeklik Buğday (Triticum aestivum L.) Popülasyonlarından Seçilen Saf Hatların Kalite Özellikleri ve Bazı Mikro Element İçerikleri Bakımından Değerlendirilmesi (Yüksek Lisans Tezi). Bingöl Üniv. Fen Bilimleri Enst. Tarla Bitkileri Anabilim Dalı, 56s Bingöl.

Van Praag HJ, Fischer V, Riga A 1980. Fate of fertilizer nitrogen applied to winter wheat as $\mathrm{Na}^{15} \mathrm{NO}_{3}$ and $\left(15 \mathrm{NH}_{4}\right)_{2} \mathrm{SO}_{4}$ studied in microplots through a four-course rotation:2. Fixed ammonium turn-over and nitrogen reversion. Soil Sci. 130:100-105.

Velde B, Barré P 2010. Soils, Plants and Clay Minerals. Role of Clay Minerals in Critical Nutrient Exchange: Potassium and Ammonium, syf. 188-189.

Yılmaz K 1990. Harran Ovası Topraklarının Mineralojik Karakterizasyonları (Doktora Tezi), Ç. Ü. Fen Bilimleri Ens Toprak Ana Bilim Dalı., 89s Adana.

Yılmaz K, Sayın M 1998. Çukurova Bölgesi Yaygın Toprak Serilerinde Çarpım Faktörü Yöntemi ile Kantitatif Kil Analizi, KSÜ Fen ve Mühendislik Dergisi 2(1): 36-46. 